\title{
Corpo e aprendizagem informal
}

Resumo: O artigo enfoca a contribuição do corpo humano para os processos (informais) de aprendizagem e desdobra a tese de que toda aquisição de habilidades e conhecimentos é transmitida corporalmente e praticamente. Ele parte de um amplo entendimento da aprendizagem que não se limita a contextos institucionalizados, mas o entende como um momento de toda prática social. Usando vários exemplos empíricos, a aprendizagem é trazido à luz como um processo de experiência no qual os sujeitos se formam "holisticamente". São formadas habilidades de percepção, de sentir e reconhecimento entre outras, que permitem ao indivíduo "tomar parte do jogo de maneira competente em suas práticas" e também agir de maneira reflexiva, crítica ou transgressora em relação a eles. No fundo, essas considerações teóricas, apresento finalmente dois cenários de aprendizagem e suas práticas: um exemplo da acrobacia e um exemplo da cena do movimento urbano. Ao mesmo tempo, o conhecimento - necessariamente seletivo e realístico - do estado da pesquisa empírica sobre a conexão entre corporalidade e aprendizagem informal deve ser expandido.

Palavras-chave: corpo; didática informal; mimese social; inteligência prática; reflexão prática.
Reiner Hildebrandt-Stramann Universidade Técnica de Braunschweig/ Alemanha R.Hildebrandt-Stramann@tu-bs.de

\section{Introdução}

Em 1986, Hildebrandt e Laging ainda podiam escrever em sua abordagem científico-sujetivada do conceito de aprendizagem que, na consciência pública, a aprendizagem estava quase exclusivamente associada ao ensino-aprendizagem institucionalizado na escola. (HILDEBRANDT; LAGING, 1986) De acordo com esse entendimento, os processos de aprendizagem são o resultado de ensino sistemático que exige um desnível de competências entre professores e alunos. Essa visão da aprendizagem parece ter mudado muito até hoje, no contexto das demandas de uma sociedade contemporânea que se vê em constante mudança. O conceito de aprendizagem não é mais o mesmo de algumas décadas atrás, em que ela foi equiparada com um ser ensinado sob as condições estandardizadas da escola, da formação profissional e da formação continuada. Pelo contrário, aprendizagem hoje é entendida como um processo que sempre e em toda parte da vida ocorre - e deve ocorrer para garantir a empregabilidade (employability) das pessoas em condições de vida incertas: na vida cotidiana, na família e no peer group (grupo de amigos), no voluntariado ou no trabalho.

Também na discussão didática e na pesquisa sobre o ensino-aprendizagem, a aprendizagem não é mais entendida como uma 
instrução no sentido de instrução direcionada ao conhecimento (proposicional), mas como uma apropriação de conhecimento e capacidade, ou seja, entendida como um processo de construção subjetiva. A atenção crescente à aprendizagem informal, às demandas de políticas educacionais e aos conceitos de "aprendizagem ao longo da vida", bem como ao desenvolvimento de competência e conhecimento em situações de ação paradigmáticas do trabalho, vida cotidiana e jogo, testemunham essa mudança de significado. Por exemplo, Lave e Wenger (1991) mostram em seus estudos sobre aprendizagem situacional em "Comunidades de Prática" (Communities of Practice) em que medida as pessoas aprendem que as pessoas aprendem por toda parte onde eles praticam algo juntos. Com base em observações empíricas eles sugerem que a aprendizagem não deve mais ser reduzida a uma transferência de cima para baixo, "unidirecional", de passagem do conhecimento do professor para o aluno, mas sim que seja situada nas interações da prática social. Isso significa uma descentralização, "deslimitação" e uma deshierarquização do seu conceito em que a aprendizagem se dissocia das meras intenções pedagógicas e não é mais vista como uma forma especialmente institucionalizada de prática social (LAVE; WENGER, 1991, p. 37), mas vista como um elemento inerente a toda prática, onde todos os envolvidos aprendem uns com os outros (ver também NICOLINI, 2012, p. 86; WENGER, 1998).

Com ênfase numa aprendizagem descentralizada, distribuída em todos os contextos possíveis de ação e em diferentes atores, as pesquisas mais recentes sobre aprendizagem se encontram com reflexões em torno de uma teoria da prática social que é discutida sobretudo na sociologia (cf. HILLEBRANDT, 2014, NICOLLINI, 2012, RECKWITZ, 2003). As considerações reunidas sob essa teoria enfatizam a materialidade e a corporalidade da prática. Eles chamam a atenção para o fato de que a prática humana - e, portanto, também toda aprendizagem - está entrelaçada com "participantes" não humanos, com coisas naturais e artefatos técnicos, com arquiteturas, ferramentas, linguagem e também outros seres vivos que estão, em princípio, vinculados a processos corporais nos quais as ordens sociais e seus sujeitos são performativamente (re)produzidos e modificados.

A percepção de que a aprendizagem está ligada ao corpo não se aplica, apenas, do ponto de vista teórico-prático, à aquisição de habilidades práticas, como aos esportes, música ou artesanato, 
mas também quando, à primeira vista, se trata exclusivamente da aquisição de habilidades cognitivas. Cada tipo de atividade "de dirigir um caminhão grande a tocar piano e apresentar evidências matemáticas" (BERGMANN, 2005, p. 640) - tem que, como é enfatizado, ser aprendido como uma atividade prática sob a participação do corpo e coisas em arranjos sociomateriais específicos.
1 Merleau Ponty (2011) diferencia entre um corpo sujetivo e um corpo objetivo. O corpo subjetivo corresponde ao corpo vivido, o corpo sensorial, o corpo objetivo corresponde ao corpo físico, o corpo externo, que pode ser objetivado

\section{Aprendizagem e corpo}

Não é possível aprender de maneira diferente do que se aprende com o corpo, porque os homens estão com o corpo no mundo (comp. MERLEAU-PONTY, 2011). Com essa acentuação do ser corporalmente situado no mundo, também é dito que as pessoas não agem e não aprendem com o corpo no sentido em que o corpo seria o instrumento de uma mente autônoma e sem corpo, mas que eles aprendem como corpo - e isso desde o nascimento como se observa quando os bebês se esticam para pegar coisas que encontram como "complexas, como um desafio" (WALDENFELS, 1994, p. 482) e tentam pega-las. Movendo-se, tateando e sentindo, eles lidam com seu ambiente e literalmente compreendem pegando quase tudo o que encontram - rostos, cabelos, controles remotos, roupas etc. Essas coisas acontecem com eles o tempo todo - mas também com o próprio corpo - ao lidarem com objetos e resistências. O próprio corpo também é vivenciado como resistência ao aprender com o corpo, por exemplo, quando a criança aprende a andar e está sempre exposta ao risco de perder o equilíbrio corporal. A luta contra a gravidade é totalmente corporal. Apreendendo eles precisam se organizar para vencer essas dificuldades, por fim, por exemplo vencer a luta com o ziper do anoraque enquanto se veste.

As abordagens biográficas da relação entre corpo e aprendizado já apontaram para o significado individual de experiências sensíveis de aprendizagem. Nessas abordagens, o corpo não é entendido apenas como uma matéria a ser disciplinado ou trabalhado, nem como um mero instrumento de ação, mas como um "ponto zero" de orientação, como uma maneira pré-consciente de acesso ao mundo e como uma superfície de ressonância para a "vida vivida" (ABRAHAM, 2002, p. 414), isto significa fenomenologicamente como corpo subjetivo. ${ }^{1}$ (MERLEAU-PONTY, 2011) No entanto, as questões 

representada aqui.. sobre sua mutabilidade histórica, sua construção social e sua função social nas práticas socias passam para o segundo plano. Portanto, existe o risco de ser negligenciado desde que o corpo objeto (no sentido de algo observável) e o corpo sujeito - no sentido de capacidades de sentir e capacidades de auto-organização cinestésica - não permaneçam como são: inicialmente movimentos absolutamente reflexivos que tornam-se gradualmente movimentos (técnicos) de habilidades como "técnicas corporais" "BODY TECHNIQUES", (MAUSS, 1989), que se adaptam funcionalmente ao ambiente e aos objetos nos quais e com os quais a criança em crescimento se move e com a qual ela lida. Ao apalpar, tocar (e através de tocar entender) e experimentar, os movimentos e o sentido de sentir do corpo, ela se adapta à ordem do ambiente.

Essa ordem é uma ordem material, simbólica e normativa ao mesmo tempo. Em sua objetividade é sempre, também, uma ordem importante, cheia de exigências e imperativos comportamentais. Como regra, os alunos também são mostrados por outras pessoas - pais, colegas etc. - como ou em que forma (estilística, estética) algo deve ser feito para ser reconhecível e onde existem os limites para o que está fora de uma faixa normal do inteligível e reconhecível que é dado como certo. Nesse sentido, o praxeólogo Pierre Bourdieu (1979, p. 60) foi capaz de escrever uma frase muito citada:

As crianças mostraram 'atenção extraordinária aos gestos e posturas que compõem o adulto certo aos seus olhos: em outras palavras, para uma certa caminhada, uma posição específica da cabeça, um franzir do rosto, pelas respectivas formas de sentar [...], tudo isso em conexão com um tom de voz particular, uma maneira de falar e - como poderia ser diferente - com um conteúdo específico de consciência'.

Com isso, ele ilustra a "persuasão secreta" de uma pedagogia informal implícita na prática cotidiana, que é capaz de "integrar uma cosmologia completa, ética, metafísica e política [...] através de uma prática e imitação de atitudes e movimentos". (BOURDIEU, 1979, p. 200) A aprendizagem é considerada uma ordem multidimensional do social. É "traduzida" não apenas em uma ordem subjetiva de movimento" e corpo, mas em conexão com ele também, por meio de uma ordem cognitiva, de modo que o indivíduo está conectado ao seu ambiente de mundo vivido, tanto física quanto mentalmente, motoramente, cognitivamente e afetivamente. ${ }^{2}$ 
Desse ponto de vista, a aprendizagem é um processo de experiência em que o sujeito se forma "holisticamente" até um certo ponto. Nesse processo, o organismo humano forma um tipo de rede de disposição na forma de esquemas de percepção, sentimento, reconhecimento e julgamento, que inclue ativamente todas as impressões e experiências sensoriais, e as modifica continuamente. Isso também significa que através desses esquemas nem tudo é assimilado em relação ao que esse organismo encontra no mundo, mas que apenas certas -características de seu co-ambiente ou situações de ação concretas são registradas, para as quais ele já desenvolveu "pontos de acoplamento" que podem ser ativados dependendo da situação. Essa visão, em última análise, é ligada à uma visão do pragmatista John Dewey (1979) segundo a qual a experiência tem uma função constitutiva e não presumida.

\section{Corpo, aprendizagem e mímese social}

O conceito de mímese social (GEBAUER; WULF, 1998) diz respeito a um instrumento teórico que permite explicar a gênese de uma subjetividade "autônoma limitada" na relação corporal prática com outros participantes. Este conceito descreve "um amplo espectro de possíveis relações entre um mundo criado pelo homem e um mundo anterior que é considerado como real ou que é postulado, hipostatizado ou fictício." (GEBAUER; WULF, 1998, p. 16) Atos miméticos não são qualquer referências de um mundo "como se" a um mundo "real" anteriormente assumido, mas relações corporais no sentido de "movimentos que se referem a outros movimentos". (GEBAUER; WULF, 1998, p. 11) Eles executam um movimento ou gesto físico "novamente" e ao mesmo tempo variam de forma mais ou menos criativa. Neste caso, o significado associado ao movimento rastreado e sua codificação simbólica é sempre retomado, rearticulado e modificado. Quando as crianças imitam (não copiam!) uma "certa caminhada" (BOURDIEU, 1979, p. 60), ao mesmo tempo elas também invocam um horizonte histórico de significado que está vinculado a esse tipo de caminhada e a modelam por conta própria. Nesse sentido, tornar-se semelhante cria algo único. Tecida nessa rede social de referências corpo-práticas, que se estabelece no modo de mímese social, é uma didática informal. Através de uma mistura de referências explícitas e reprimendas subliminares, linguísticas e não linguísticas, mostram-se os participantes 
atuando numa prática, como aulas na escola ou jogo de futebol, o que está acontecendo e como é feito. Em uma rede de endereços socializados, por exemplo, os novatos aprendem a observar a si mesmo, continuamente, com os olhos de outros, para corrigir-se e mante-los em ordem.

Essa socialização mútua nas práticas típicas de uma área social ou de uma instituição não leva, inevitavelmente, à adaptação às estruturas existentes e à submissão a normas hegemônicas. Ao contrário, também é formada à luz de uma inteligência prática específica. Isso significa a capacidade de se comportar socialmente, ou seja, de produzir uma sensibilidade social.

Com essa forma de inteligência, que pode ser descrito com "o conceito de senso prático" do Pierre Bourdieu (1987), não trata-se de uma habilidade puramente cognitiva, mas da competência de um corpo socializado. A essência desses conceitos é a tematização das habilidades incorporadas, das habilidades de percepção e de sentido, que não são tematizadas nas teorias de aprendizagem cognitiva. Tais habilidades possibilitam que os indivíduos ajam adequadamente em uma situação, mesmo sob pressão do tempo. Embora em certas abordagens da teoria da prática atual seja habitual preferir ver no corpo socializado um meio de rotinas que mantêm uma prática "em andamento" e, portanto, contribuem para a reprodução da ordem social (RECKWITZ, 2003, p. 289), esse outro corpo está reconhecido em abordagens adicionais sobre a capacidade de "refletir práticamente" (BOURDIEU, 2001, p. 209), que possibilita avaliar uma ação durante sua execução e, se necessário, corrigir. Refletir dessa maneira é menos uma reflexão cognitiva do que uma reflexão sensitiva no sentido de uma auto-organização e correção cinestésicas. O conceito de cinestesia, em particular, deixa claro quão porosas são as fronteiras entre experiências corporal-sensoriais e processos de pensamento consciente. (BATESON, 1979) O conceito da cinestesia explica bem claro como o corpo, o pensamento e a fala se relacionam entre si em ação e na aprendizagem. Com a aprendizagem, o treinamento e a execução de padrões e gestos corporais (movimentos), sempre são formadas percepções corporais, atitudes de habilidades práticas de reflexão, que garantem a orientação de um sujeito na prática.

Nos últimos tempos, foram elaborados conceitos de "corporalidade da execução", que são ligados com as declarações anteriores 
(comp. HILDEBRANDT-STRAMANN, 2013). Esses conceitos tentam explicar dois aspectos:

1. o corpo não permanece idêntico na aprendizagem (mimética), na prática e no treinamento, mas suas diversas disposições são especificamente modeladas em práticas díspares;

2. o corpo deve sempre estar em um modo reflexivo de execução - cinestesicamente através da percepção e apreciação sensorial - na forma da prática "envolvente".

Com esses conceitos, torna-se possível não entender o corpo decifrado como 'socialmente construído' como um mero espelho da ordem normativa de uma sociedade, como acontece nas ciências sociais e culturais, mas também trazer à vista que o que foi aprendido como um repertório de disposições, a amplitude do conhecimento no corpo socializado também pode ser "usada"para "interpretar" essa ordem "teimosamente": a qualquer momento, um impulso pode sair do corpo da execução para se desviar da norma e para a inovação cultural, ${ }^{3}$ sua autorreflexividade cinestésica capacita o corpo tocar o mundo, sentir "potencias da situação", pegar-lo e construir uma ponte imediata (mas não repentina) para outros participantes; o corpo não é apenas um executor de necessidades, mas também uma fonte de subversão e rebelião. (SUAUD, 2011) No pano de fundo dessas considerações teóricas, tratarei de dois contextos de aprendizagem e de suas práticas como exemplos. Pretende-se também expandir a percepção - inevitavelmente seletiva e destacada - do estado da pesquisa empírica sobre a conexão entre corporalidade e aprendizagem. Considero comparativamente um cenário institucionalizado e não institucionalizado, bem como a interação de momentos formais e informais de aprendizagem.

\section{Dois casos de aprendizagem corporal em duas áreas sociais}

Com base nessas considerações teóricas, apresento a seguir dois cenários de aprendizagem exemplares e suas práticas. Ao mesmo tempo, a visão - inevitavelmente seletiva - é pretendida ser expandido no estado da pesquisa empírica sobre a conexão entre fisicalidade e aprendizagem. Apresento um exemplo de aprendizagem
3 Como exemplo atual serve o ajoelhar dos atletas que é uma expressão de solidariedade ao movimento "Lives matter", ou seja uma demonstração física contra a opressão de grupos populacionais marginalizados. A história da cultura do corpo e do movimento brasileira está repleta de exemplos como, por exemplo, a importância histórico-política da capoeira. 
institucionalizada e não institucionalizada, bem como a interação de momentos formais e informais de aprendizagem.

\section{A formação da co-jogabilidade em acrobacias esportivas}

Meu primeiro exemplo é um estudo etnográfico sobre o treinamento de um grupo de acrobatas ativos em alto nível. Acrobacia esportiva é um esporte de equipe que inclui a construção de pirâmides humanas ou a execução coletiva de cambalhotas (saltos) lançadas. As figuras são realizadas em "responsabilidade distribuída das ações" (RAMMERT; SCHULZ-SCHAEFFER, 2002), ou seja, as ações dos participantes são altamente interdependentes. Dessa interdependência resulta em uma enorme suscetibilidade à falha e uma alta probabilidade de falha: mesmo a menor incerteza de um participante pode levar o número inteiro a romper ou desabar.

O "jogar junto" nessas constelações arriscadas não exige apenas que os acrobatas dominem, rotineiramente, um certo repertório de técnicas e movimentos corporais. Pelo contrário, no treinamento tem que ser praticadas as habilidades de perceber erros enquanto estão sendo executados, variar rotinas dependendo da situação e avaliar a própria pessoa e as ações dos outros jogadores (criticamente). Essas habilidades formam a base para a execução de figuras acrobáticas exigentes em uma divisão do trabalho, lidando com incertezas, corrigindo-se umas às outras e mudando criativamente uma prática bem praticada ou sendo capaz de inventar algo novo.

As análises microscópicas dos episódios individuais de treinamento mostram que, por assim dizer, por trás da didática formal do treinamento iniciado pelo treinador, interações discretas entre os atletas, que à segunda vista provam ser igualmente funcionais e importantes, continuam a ocorrer: no sentido do conceito da "Community of Practice", os atletas transmitem o conhecimento necessário para participar num tipo de uma pedagogia implícita. Isso significa que eles se capacitam mutuamente, transmitem coragem e confiança uns aos outros por meio de atos de fala encorajadores e contribuições afetivas (por exemplo contatos corporais) e, portanto, oganizam, assim, informalmente uma proteção em segundo plano para as açoes formais do treinador. Ao mesmo tempo torna claro o cruzamento de um aprendizagem mimético (mudo) com instruções e correções faladas que são direcionadas para sequências de movimentos individuais e partes do corpo relevantes para o exercício. 
Tais "discussões/conferências" da prática física baseam-se num sentido corporal da pessoa que corrige, sua capacidade socializada da corealisação virtual dos movimentos observados.

\section{Aprendizagem em cenas informais de movimento}

O cenário informal "esporte de tendência" serve como um segundo exemplo. Nos trabalhos sociológicos (esportivos), a aprendizagem que ocorre nessa forma social é examinada principalmente usando palavras-chave como "comunização pós-tradicional'", "aquisição de estilo' ou "autoformação"' e "autotransformação". Como mostra Stern (2010), a aprendizagem de movimentos e estilos ocorre não apenas de passagem, mas também intencionalmente usando os meios técnicos mais modernos. (STERN, 2010, p. 167) Por um lado, imagens tecnicamente produzidas e distribuidas pela mídia servem para preservar e divulgar um movimento e estilo típicos da cena; por outro, abrem uma perspectiva analítico-reflexiva para os atores em suas próprias ações.

Ao visualizar e discutir o material da imagem juntos, por exemplo, com vista a critérios estéticos, é gerado um conhecimento visual detalhado, com a ajuda de quais movimentos podem ser variados e novas variações podem ser exploradas: as maquinas fotográficas, o celular e o conhecimento de imagem produzido tecnicamente tornam-se co-atores constitutivos do aprendizagem de movimento e de estilo (STERN, 2010, p. 169-173), práticas corporais e de mídia se entrelaçam produtivamente.

Em outros estudos, os movimentos de deslizar, rolar, pular e pairar, característicos de vários esportes de tendência, são identificados como práticas de autoeducação, da auto-certificação e da autotransformação através da experiência de evidências. (GUGUTZER, 2004) Nesse contexto está sendo discutido se essas são práticas criativas de subversão ou autoajustes práticos corporais aos requisitos da sociedade pós-fordista, que chama seus membros a mudarem continuamente para ser capazes de lidar de modo flexível e criativo com incertezas e surpresas.

Nesse contexto, a constituição dos processos de aprendizagem é interessante. Quando, por exemplo, o skatista não está andando de skate, ele está constantemente treinando. Eles treinam truques com os quais podem girar, por exemplo, uma prancha de skate enquanto dirigem em torno de seu próprio eixo longitudinal. Eles 
treinam saltos para saltar por cima das escadas ou para descer em um corrimão.

O modelo de aprendizagem que caracteriza essa aprendizagem informal é o de "aprendizagem por tentativa e erro" (trial and error) ou "aprendizagem por modelo". (BANDURA, 1986) Os alunos observam os movimentos dos especialistas, dão indicações uns aos outros, fazem sugestões de aprendizagem e treinam. Nesses processos de autoaprendizagem são formadas habilidades sensíveis de movimento, como por exemplo a capacidade de equilíbrio ou a capacidade cinestésica. A gente também pode dizer que o corpo se torna seguro para se mover. Tais exemplos informais de aprendizagem deixam claro:

- o caráter dialógico do movimento: aprendo algo sobre o ambiente do movimento através do movimento, reconheço os significados do movimento que paredes, grades e escadas podem ter. No entanto, só posso conhecer esses significados se realmente lidar com essas situações urbanas de uma maneira móvel. Nesse sentido, o movimento também é um meio de conhecimento. (KUNZ, 2010; TAMBOER, 1979; TREBELS, 2010;). Ao mesmo tempo, também aprendo algo sobre mim quando a experimentação com o movimento faz algo comigo;

- experimento-me como jeitoso e corajoso, avaliando o risco, enfim, reconhecendo meus limites;

- que a cidade não é apenas um terreno de restrição de movimento, mas também oferece varias opções de movimento que os skatistas podem explorar de maneira criativa.

- os skatistas têm um alto nível da capaciadade de movimento que adquirem por meio de treinamento consciente e praticam em grupos auto-selecionados em horários auto determinados. Apesar do caráter do risco, do ponto de vista do skatista, a segurança é fundamental, pois as lesões simplesmente prejudicam a capacidade de agir. 


\section{Conclusão}

No contexto dos estudos teórico-empíricos apresentados em linhas gerais, várias intenções de pesquisa podem ser identificadas com relação à conexão entre corpo e aprendizagem informal. Em minha opinião, um primeiro desiterato diz respeito à questão de saber qual a inter-relação entre a prática corporal e a prática linguistica que é observada empiricamente em diferentes contextos, o que significa a distinção estabelecida entre conhecimento explícito e implícito e aprendizagem. É importante esclarecer se essa distinção marca dois polos conflitantes ou mesmo exclusivos de conhecimento e aprendizagem ou apenas os dois pontos finais de um continuum. Outra questão de pesquisa intimamente relacionada ao pensamento anterior é se e sob quais condições implícitas e explícitas, ao aprender e participar de práticas, interagem "produtivamente" ou dificultam e "interferem" entre si.

A segunda intenção trata do uso de análises microetnográficas detalhadas para investigar as relações entre a formação ou transformação do corpo e seus movimentos, bem como a capacidade de percepção corporal e as habilidades sensoriais em diferentes contextos e práticas.

Finalmente, uma terceira tarefa seria esclarecer empirica e analiticamente as condições sob as quais os atores individuais, devido às suas disposições físico-mentais adquiridas, dificultam ou até mesmo tornam mais difícil a participação em certas práticas (aulas, trabalho, brincadeira, etc.). No centro das atenções chegariam "relacionamentos adequados" entre o conhecimento incorporado (habilidade, competências) dos respectivos atores; e entre esse conhecimento incorporado e às histórias objetivadas nas coisas e arranjos materiais envolvidos e os "significados dos objetos". (HOLZKAMP, 1995)

A esse respeito, pergunta-se: existem ressonâncias ou dissonâncias? A história incorporada e a história objetivada podem entrar em um relacionamento ou não? Em vez de conceber o corpo como uma matéria-prima, arbitrariamente moldável para os processos de aprendizagem, os momentos e situações de sua indisponibilidade e incapacidade também precisariam ser sistematicamente levados em consideração e iluminados empiricamente, para revelarem em que condições os corpos se opõem à aprendizagem e à adaptação às práticas, "teimosamente". 


\title{
Body and informal learning
}

\begin{abstract}
The article focuses on the contribution of the human body to (informal) learning processes and unfolds the thesis that all skill and knowledge acquisition is conveyed physically and practically. He starts from a broad understanding of learning that does not limit it to institutionalized settings, but sees it as a moment of every social practice. Using various empirical examples, learning is brought into view as a process of experience in which subjects are formed "holistically": Abilities to perceive, sense and recognize are formed, which enable individuals to "play competently" in practices and also to act reflexively, critically or subversively towards them. On the background of these theoretical considerations, I will finally present two learning settings and their practices: an example from acrobatics and an example from the urban movement scene. At the same time, the - necessarily selective and highlight-like - insight into the state of empirical research on the connection between physicality and informal learning should be expanded.
\end{abstract}

Keywords: body; informal didactics; social mimesis; practical intelligence; practical reflection

\section{Cuerpo y apendizaje informal}

Resume: El artículo se centra en la contribución del cuerpo humano a los procesos de aprendizaje (informal) y desarrolla la tesis de que todas las habilidades y conocimientos se transmiten corporalmente y prácticamente. Comienza con una comprensión amplia del aprendizaje que no lo limita a contestos institucionalizados, sino que lo ve como un momento de toda práctica social. Usando varios ejemplos empíricos, el aprendizaje se presenta como un proceso de experiencia en el cual los sujetos se forman "holísticamente": Se forman habilidades para percibir, sentir y reconocer, que permiten a los individuos "jugar de manera competente en las prácticas" y también actuar de manera reflexiva, crítica o subversiva hacia ellas. En el contexto de estas consideraciones teóricas, finalmente presento dos escenarios de aprendizaje y sus prácticas: un ejemplo de la acrobacia y un ejemplo de la escena del movimiento urbano. Al mismo tiempo, se ampliará la percepción, necesariamente selectiva y parecida a lo destacado, del estado de la investigación empírica sobre la conexión entre lo físico y el aprendizaje informal.

Palabras clave: cuerpo; didáctica informal; mimesis social; inteligencia práctica; reflexión práctica.

\section{Referências}

\begin{abstract}
ABRAHAM, A. Der Körper im biographischen Kontext. Ein wissenssoziologischer Beitrag. Wiesbaden: Westdeutscher Verlag, 2002.

BANDURA, A. Social Cognitive Theory. In: VASTA, R. (ed.). Annals of Child Development. Six Theories of Child Development. 6. ed. Greenwich, CT: JAI, 1989. p. 1-60.
\end{abstract}

BATESON, G. Mind and Nature: A Necessary Unity. Cresskill, NJ: Bantam Books, 1979. 
BERGMANN, J. Studies of Work. In: RAUNER, F. (Hg.): Handbuch der Berufsbildungsforschung. Bielefeld: Bertelsmann, 2005. p. 639-646.

BOURDIEU, P. Entwurf einer Theorie der Praxis. Frankfurt a. M.:

Suhrkamp, 1979.

BOURDIEU, P. Sozialer Sinn. Kritik der theoretischen Vernunft. Frankfurt a M.: Suhrkamp, 1987.

BOURDIEU, P. Meditationen. Zur Kritik der scholastischen Vernunft.

Frankfurt a. M.: Suhrkamp, 2001.

DEWEY, J. Democracia e Educação. 4. ed. São Paulo: Cia. Editora Nacional, 1979..

GEBAUER, G.; WULF, C. Spiel Ritual Geste. Mimetisches Handeln in der sozialen Welt. Reinbek: Rowohlt, 1998.

GUGUTZER, R. Trendsport im Schnittfeld von Körper, Selbst und Gesellschaft. Leib- und körpersoziologische Überlegungen. Sport und Gesellschaft, v. 1, n. 3, p. 219-243, 2004.

HILDEBRANDT-STRAMANN, R. Visão pedagogia de movimento. In: HILDEBRANDT-STRAMANN, R. Textos pedagógicos sobre o ensino da educação fisica. Ijui: EdUnijuí, 2013. p. 105-116.

HILDEBRANDT, R; LAGING, R. Concepções abertas ao ensino da educação fisica. Rio de Janeiro: Ao Livro Técnico, 1986.

HILLEBRANDT, F. Soziologische Praxistheorien. Eine Einführung. Wiesbaden: Springer VS, 2014.

HOLZKAMP, K. Lernen. Subjektwissenschaftliche Grundlegung. Frankfurt am Main/ New York: Campus, 1995.

KUNZ, E. Transformação didático pedagógica do esporte. 9. ed. Ijuí: EdUnijuí, 2010.

LAVE, J; WENGER, E. Situated Learning. Legitimate Peripheral Participation. Cambridge: New York: Cambridge University Press, 1991.

MAUSS, Marcel. Soziologie und Anthropologie, Bd. II: Gabentausch; Soziologie und Psychologie; Todesvorstellung; Körpertechniken; Begriff der Person. Frankfurt a. M.: Fischer, 1989.

MERLEAU-PONTY, M. Fenomenologia da percepção. São Paulo: WMF Martins Fontes, 2011.

NICOLINI, D. Practice Theory, Work and Organization. An Introduction. Oxford: Oxford University Press, 2012.

RAMMERT, W.; SCHULZ-SCHAEFFER, I. Technik und Handeln. Wenn soziales Handeln sich auf menschliches Verhalten und technische Abläufe verteilt. In: RAMMERT, W.; SCHULZ-SCHAEFFER, I. (hg.): Können Maschinen handeln? Soziologische Beiträge zum Verhältnis von Mensch und Technik, Frankfurt a. M: New York: Campus, 2002. p. 11-64. 
RECKWITZ, A. Grundelemente einer Theorie sozialer Praktiken. Eine sozialtheoretische Perspektive. Zeitschrift für Soziologie, Berlin, v. 32, n. 4, p. 282-301, 2003.

STERN, M. Stil-Kulturen. Performative Konstellationen von Technik, Spiel und Risiko in neuen Sportpraktiken. Bielefeld: Transcript, 2010.

SUAUD, C. Zwischen Praxis und Reflexivität. Der Körper als Organ gesellschaftlicher Veränderung. In: SCHMIDT, R; STOCK, W.-M.; VOLBERS, J. (hg.): Zeigen. Dimensionen einer Grundtätigkeit. Weilerswist: Velbrück, 2011. p. 73-88.

TAMBOER, J. Sich Bewegen - ein Dialog zwischen Mensch und Welt. sportpädagogik Seelze, v. 3, n. 2, p. 14-19, 1979.

TREBELS, A. H. A Concepção Dialógica do Movimento Humano; uma Teoria do "Se- movimentar". In: KUNZ, E.; TREBELS, A. H. (org.). Educação física critica emancipatória. Ijui: EdUnijuí, 2010. p. 23-48.

WALDENFELS, B. Antwortregister. Frankfurt a. M.: Suhrkamp, 1994.

WENGER, E. Communities of Practice. Learning, Meaning and Identity. Cambridge: Cambridge University Press, 1998. 